Revista InTERnACIONAL de Sociología (RIS)

\title{
MOVIMIENTOS SOCIALES, RESPONSABILIDAD CORPORATIVA E INCLUSIÓN SOCIAL EN LA GLOBALIZACIÓN
}

\author{
SOCIAL MOVEMENTS, CORPORATE SOCIAL RESPONSIBILITY, \\ AND SOCIAL INCLUSION IN GLOBALIZATION
}

\author{
TomÁs AlberICH alberich@ujaen.es \\ Universidad de Jaén. España
}

\begin{abstract}
RESUMEN
En los años setenta se inaugura un ciclo de sucesivas crisis socioeconómicas hasta el comienzo en 2008 de la actual, marcada por el capitalismo especulativo que es el creciente en las dos últimas décadas y que se desarrolla al hilo de la globalización neoliberal. En el artículo se describen cuatro posiciones dominantes en los sistemas político-económicos actuales y cómo desde una de ellos (capitalismo auto-reglado) se potencia un Estado de Bienestar a la baja en favor de una Responsabilidad Social Corporativa (RSC) en alza. Mediante la utilización de tetralemas también se describen las cuatro variantes principales de la RSC y cómo son utilizadas por asociaciones no lucrativas y movimientos sociales, desde sus diferentes posturas y en sus relaciones con los ámbitos del poder público y privado, describiendo el ejemplo de las asociaciones de acción social de la discapacidad.
\end{abstract}

\section{Palabras clave}

Asociaciones de Discapacidad; Globalización, Movimientos Sociales; Responsabilidad Social Corporativa.

\section{Abstrat}

The 70s saw the inauguration of a cycle of successive socioeconomic crisis until the starting of the current crisis in 2008 , marked by speculative capitalism, which has been growing during the last two decades following the thread of neoliberal globalization. This article outlines the four main positions in the current politico-economic systems, describing how in one of them (self-regulated capitalism) the Welfare State tends to drop in favor of a rising Corporate Social Responsibility (CSR). The author uses tetralemas to describe the four main variants of the CSR and how these are used by non-profit associations and social movements, from their different approaches and relationships with the public and private institutions, analyzing the example of the associations working on the social action on disability.

\section{KEYWORDS}

Corporate Social Responsibility; Globalization; Non Profit Disability Associations; Social Movements. 


\section{Movimientos Sociales, Responsabilidad Corporativa e Inclusión SOCIAL EN LA GLOBALIZACIÓN}

El presente artículo tiene como objetivo relacionar tres conceptos: globalización, Responsabilidad Social Corporativa (RSC) y movimientos sociales, analizando su evolución en las últimas décadas. Estudiamos cómo surgen los procesos de globalización y cómo en su seno nace la filosofía empresarial de la RSC: para dar respuesta al creciente desprestigio del sistema capitalista y, en tercer lugar, analizamos cómo buena parte de los movimientos sociales y asociativos han sabido adaptarse a estas nuevas situaciones y escenarios cambiantes (hipótesis de trabajo). Las asociaciones han creado diferentes modelos de acción y de gestión y han construido diversidad de respuestas ante los problemas e interrogantes sociales con el fin de conseguir sus objetivos, planteando respuestas multi-variadas (tetralemas y multilemas) que superan los habituales dilemas (sí o no a algo, por ejemplo respecto a la RSC).

El método principal de elaboración ha sido el contraste entre el análisis de fuentes secundarias (sobre globalización y RSC) y las investigaciones directas realizadas por el autor sobre movimientos sociales y asociacionismo, y particularmente sobre asociaciones de personas con discapacidad.

\section{GLOBALIZACIÓN. UN PROCESO DE MUNDIALIZACIÓN Y DESREGULACIÓN CRECIENTE}

La globalización la podemos definir como el conjunto de procesos de comunicación, interrelación e interdependencia entre diferentes pueblos, economías y culturas que se da a nivel planetario. El aumento de las relaciones mundiales y de las influencias mutuas entre países se produce en numerosos ámbitos desde hace varios siglos pero de forma crecientemente acelerada a partir de los años ochenta y noventa del s. XX, que es cuando adquiere características definitorias propias y es a lo que hemos dado en llamar "globalización" o, en su forma predominante, "globalización neoliberal", diferenciándolo de otros procesos anteriores de mundialización o universalización, que serían las palabras más utilizadas en castellano (Taibo 2002:24). Veamos sus antecedentes más inmediatos.

Las diversas crisis del petróleo a partir de 1971 provocaron un alza de sus precios impulsada por los países productores de la OPEP, como forma de ganar poder económico y político internacional (se denominó crisis al enfrentamiento internacional por el precio y por el control de las fuentes de energía). Como acción puntual, los países no alineados y especialmente los árabes, querían ganar poder y hacer frente al expansionismo israelí en Palestina, junto a la concienciación de querer cambiar unas relaciones económicas desiguales entre unos países que vendían energía y materias primas baratas a los países industrializados (facilitando su desarrollo), mientras que ellos tenían 
que comprarles a precios muy elevados la tecnología, las patentes y los productos manufacturados (maquinaria de producción, electrodomésticos, etc.). Estos países no alineados tenían el convencimiento de que la crisis del petróleo les beneficiaría, tratando de cambiar las reglas de comercio internacional y las desiguales relaciones Norte-Sur. Reglas comerciales que, como sabemos, no consiguieron cambiar, aunque sí mejoraron sustancialmente su situación económica.

El Estado de Bienestar había comenzado su desarrollo a partir de la crisis de 1929 (la Gran Depresión), con las propuestas keynesianas y el New Deal de Roosevelt, adquiriendo un gran crecimiento en los países industrializados después de la Segunda Guerra Mundial. Había conseguido una disminución de las desigualdades sociales, un paulatino aumento de los impuestos, con una ligera disminución de las tasas de ganancia empresariales, y un aumento del poder de los sindicatos y organizaciones sociales en estos países. Además, el desarrollo del Estado de Bienestar se había convertido en el mejor antídoto para las veleidades revolucionarias que podrían haberse contagiado después de las revoluciones comunistas soviética y china.

Pero, como comentábamos, a partir de 1971-1973 se producen una serie de crisis que van a tener notables repercusiones en el modelo de Estado existente hasta entonces. ¿Cómo solventó el capitalismo estas crisis — de energía y de Estado de Bienestar caros- para mantener o incluso incrementar las tasas de beneficio empresariales? A unos años de ahorro energético y de reestructuración industrial continuaron cinco tipos de respuestas en los años ochenta, en buena parte impulsadas desde el tándem $\mathrm{R}$. Reagan-M. Thatcher:

1. Disminución de costes fiscales a las empresas y a las grandes rentas mediante la reducción de impuestos. Y disminución de los controles, reducción del papel fiscalizador de los Estados en nombre de la "libertad" y de las nuevas palabrasfetiche: "flexibilidad" y, más aún, "desregulación" que es "la palabra de moda y el principio estratégico elogiado y aplicado activamente por cualquiera que tenga poder. Hay demanda de desregulación porque los poderosos no desean ser 'regulados', tener limitada su libertad de elección y constreñida su libertad de movimientos; pero también porque ya no tienen interés en regular a otros" (Bauman 2006: 35).

2. La reducción de impuestos implica una disminución de ingresos del Estado y, como consecuencia, la paulatina disminución del Estado de Bienestar, ya que comienza a no poder hacer frente a los servicios que hasta entonces había prestado. Disminución de las políticas de protección social (reducción de costes en sanidad, educación, prestaciones por desempleo, privatizaciones...). Consecuencia: aumento de las desigualdades sociales.

3. Abaratando costes de producción. Disminución de los salarios reales y de los derechos laborales: menos seguridad en el empleo, descenso de la indemnización por despido, aumento del empleo precario, más eventualidad,... Consecuencia: aumento de las carencias sociales, de las desigualdades 
económicas internas y de la inseguridad. Una sociedad en la que todo fluye, todo se disipa, todo cambia, y en la que los derechos y los valores fundamentales ya no tienen una base sólida, se nos escapan, se nos escurren entre las manos; es la "modernidad líquida" tan gráficamente expresada por Z. Bauman (2005). Se pasó de los derechos sólidos como rocas a los miniderechos flexibles y líquidos. Ahora, con la Gran Crisis o la Gran Recesión, podemos decir que estamos pasando a la modernidad gaseosa, con derechos invisibles.

4. Para que las reformas citadas se pudieran llevar a cabo se realiza el mayor enfrentamiento desde la Seguda Guerra Mundial con sindicatos, organizaciones obreras y movimientos sociales que se oponían a estas medidas. Enfrentamiento que se salda, comenzando por Reino Unido y continuando en la mayoría de los países, con una disminución del poder de sindicatos y MM. SS. y con la paulatina asunción posterior, desde las organizaciones socialdemócratas, de buena parte del nuevo ideario conservador neoliberal (a través de propuestas como la de la tercera vía, socialdemocracia liberal,...).

5. Las grandes empresas comienzan la conquista de nuevos mercados. La expansión de las multinacionales lleva a la creación de las grandes corporaciones empresariales "transnacionales". Una multinacional es una gran empresa nacional que se expande y opera en varios países, las transnacionales actúan a nivel mundial y difícilmente se las puede identificar con un Estado u otro, ya que su política y sus intereses son los suyos propios y su mercado es global (aunque se las siga asociando con su país de origen). Las economías nacionales pierden poder 0 se desmantelan en algunos sectores, se producen los primeros procesos de deslocalización de las empresas, se inicia, en definitiva, el proceso de mundialización económica conocido como globalización. Proceso que coge mayor impulso a partir de 1989 con el desmantelamiento de la URSS: el capitalismo ya no tiene competidores políticos, se auto-reconoce como capitalismo sin fronteras. Consecuencia: aumento de las desigualdades territoriales internacionales.

La batalla de las ideas había comenzado antes. Desde los años setenta las propuestas de los think-tanks fueron en el sentido de "1) obligar a los norteamericanos y al mundo entero a regresar a los parámetros del capitalismo salvaje; 2) imponer un retorno a los 'genuinos valores americanos' de corte puritano (...) Se estaba tramando la revolución de los muy ricos, como la bautizó Galbraith (...) A la altura de 1980 los neoliberales se hicieron con las riendas del Fondo Monetario Internacional y del Banco Mundial, dejando fuera de combate a varias generaciones de socialdemócratas" (García-Rosales y Penella 2011:21-27). Aunque no todos los países estuvieron en el impulso de esta lógica neoliberal en los años ochenta, como por ejemplo Francia o España, por distintos motivos, lo cierto es que va penetrando internacionalmente y es claramente mayoritario desde los años noventa. 


\section{GLOBALIZACIÓN}

La globalización, como hemos dicho, es un proceso de intercomunicación mundial y un fenómeno histórico natural: significa mestizaje, fusión y contaminación entre culturas, economías, tecnologías... Proceso que se ha dado lenta y paulatinamente desde el mismo origen histórico de las civilizaciones y especialmente desde que estas tienen un conocimiento cierto del conjunto de las dimensiones de nuestro planeta. Pero la globalización neoliberal, predominante desde los años ochenta/noventa, es un proceso nuevo, diferente a lo que había existido antes, ya que quiere imponer sus reglas de mercado como únicas, y que se da en al menos cinco ámbitos diferentes:

1. En la Cultura. Es la globalización neoliberal más antigua, que comienza con el proceso de exportación del modelo de vida norteamericano (american way of life) a través de su potente industria cultural: películas de Hollywood, música, comida rápida, bebida - refrescos de cola — desde hace varias décadas. Se vende que eso es lo moderno, que es la cultura abierta de la libertad. Potenciar o proteger las culturas locales (regionales, nacionales...) es algo antiguo, retrógrado.

2. En la Economía. Desregulación y deslocalización, libertad para el movimiento de capitales, principalmente del capital financiero especulativo (que se mueve gratis a nivel mundial, sin tasas) y, en menor medida, de la industria, que sigue teniendo aranceles aunque menos que antes. Libertad para los movimientos económicos pero no para una de sus bases fundamentales, los recursos humanos, no para las personas.

3. Tecnológica. Especialmente de las nuevas tecnologías de la Información y la Comunicación (TIC) pero se da en todos los sectores: globalización en la investigación - I+D+i, biomedicina, automatización— Los avances tecnológicos son la parte más visible e inmediata de la globalización, con apariencia de instantánea.

4. Globalización del crimen organizado, de las actividades económicas ilegales y alegales: tráfico de drogas ilegales, de armamento, tráfico ilegal de mercancías. El de obras de arte y de falsificaciones es el que más dinero mueve después de los dos anteriores (drogas y armamento). Y tráfico ilegal de personas. Con la globalización, el dinero en paraísos fiscales no ha dejado de aumentar. Igual que el porcentaje de la economía en manos del crimen organizado y de las mafias internacionales, según todos los estudios que se van realizando (Vidal-Beneyto, 2010:241 y ss. Garzón, 2005. De la Corte y Giménez-Salinas, 2010. Forgiore, F. 2010).

5. Globalización política y social, de los derechos humanos y de la democracia que es la que menos se da o que menos se respeta. Promovida por organismos y acuerdos internacionales, la ONU, protocolos de protección ambiental (como el de Kioto y posteriores), Corte Penal Internacional, etc., y la impulsada desde organizaciones y movimientos sociales internacionales (Green Peace, Amnistía Internacional, movimientos alterglobalizadores y foros sociales,...). 
Los cinco tipos o formas en que la globalización se produce están interconectados, incluso superpuestos. La revolución tecnológica, a partir de la tercera revolución industrial, ha facilitado el desarrollo de las otras globalizaciones y ha dado soporte a la globalización mediática. A su vez el acrecentado poder de los nuevos mass media ha impulsado las globalizaciones e incluso ha impuesto sus modelos y sus diversas visiones globalizadoras. Para Manuel Castells vivimos en la "sociedad red, que es a la Era de la Información lo que la sociedad industrial fue a la Era Industrial" (Castells, 2010:27). Como veremos, los modelos político-económicos son diversos y, como también indica este autor, a pesar de la globalización sigue existiendo esa pluralidad y los EstadoNación permanecen, pero con unas reglas de juego diferentes. En lo que se coincide es en el enorme poder la comunicación: "Poder es algo más que comunicación, y comunicación es algo más que poder. Pero el poder depende del control de la comunicación, al igual que el contrapoder depende de romper dicho control" (Castells, 2010: 23). (En las revoluciones de la primavera árabe y en los movimientos sociales de indignados hemos comprobado lo acertado de esta afirmación).

Para el análisis social de la globalización debemos tener en cuenta que podemos distinguir tres niveles: los procesos mundiales de interdependencia creciente (los cuatro primeros ejes citados), las nuevas instituciones de acción global creadas al hilo de esas interdependencias (principalmente en el $2^{\circ}$ y $5^{\circ}$ citado) y los cambios que en su conjunto provoca lo anterior en el interior de los estados y de los territorios locales (aspecto menos estudiado). En palabras de Saskia Sassen hay que diferenciar "la formación de procesos y de instituciones explícitamente globales, como por ejemplo la Organización Mundial de Comercio, los mercados financieros internacionales, el nuevo cosmopolitismo y los Tribunales Internacionales (...) Por otro lado se encuentran los procesos que no pertenecen necesariamente a la escala global y que, sin embargo, forman parte de la globalización. Dichos procesos están inmersos en territorios y dominios institucionales que en gran parte del mundo se consideran nacionales. (...) Es posible mencionar aquí las redes transfronterizas de activistas dedicados a alguna causa local específica que también se da en escala global, como es el caso de organizaciones de defensa del medio ambiente o de defensa de los derechos humanos. También ciertos aspectos de la labor de los estados nacionales forman parte de la globalización: ejemplo son las políticas monetarias y fiscales impuestas por el FMI y por los Estados Unidos como parte de la constitución de los mercados financieros internacionales" (Sassen 2007:14).

\section{RESPUESTAS EN LOS AÑOS NOVENTA}

Después de esta introducción conceptual retornemos al recorrido histórico reciente. En los años noventa del pasado siglo ya se dijo que el capitalismo había ganado la guerra fría (desaparición de la URSS,...) pero que iba camino de perder la "guerra" contra el hambre y la miseria, contra la pobreza y el deterioro del medio ambiente. El desprestigio del sistema fue en aumento en esta década y ya no había un enemigo exterior (bloque 
comunista) al que echarle la culpa de nuestros males (aunque después apareciera la guerra contra el terrorismo). En estos años fue significativo: 1, la instauración de nuevos sistemas sociopolíticos de capitalismo salvaje a la vez que autoritario en Rusia y países ex-comunistas; 2, las nuevas hambrunas y las guerras de exterminio en África y otras zonas, ligadas a la explotación de minerales y materias primas estratégicas, fuentes energéticas y el petróleo, y la implicación de las empresas multinacionales europeas y norteamericanas en el fomento de esas guerras civiles; 3 , los nuevos escándalos de corrupción internos al sistema y por la ingeniería contable, de Enron, Parmalat, Worl Com, ... 4, las catástrofes ecológicas de Bhopal, Exxon Valdez, Prestige, ... 5, el pinchazo de la burbuja especulativa financiera ligada a las nuevas tecnologías informáticas; 6 , la corrupción político-empresarial, junto al permisivo sistema de transacciones internacionales que permitía o toleraba el tráfico paralegal; 7, el crecimiento de los paraísos fiscales para la evasión de impuestos de las grandes fortunas, incluso en el interior de la Unión Europea; 8, el escándalo de la explotación infantil en Asia para la fabricación de ropa y material deportivo barato para nuestro consumo, etc. Este conjunto de situaciones y fenómenos conforman el panorama internacional creciente de los años noventa, hasta el punto de que un articulista se llegó a preguntar: "por favor ¿es que se quieren cargar al capitalismo desde dentro?". Como deberíamos saber ahora, ninguno de estos problemas son nuevos ni han aparecido con la crisis actual (de 2008).

¿Cuáles fueron las respuestas ante estas situaciones y ante el proceso de desprestigio del sistema en los años 90 ? Se dieron diversas respuestas desde los tres ámbitos principales que conforman la sociedad (estado, mercado y tercer Sector):

1. Desde los estados se buscó un modelo de desarrollo diferente o que al menos introdujera algunos cambios. Por un lado están las propuestas de "Desarrollo Sostenible", económico, social y medioambiental, a partir de 1992 (Cumbre de Río), principalmente a desarrollar por los Estados y las administraciones públicas locales (elaboración de Agendas 21, Cartas de Aalborg). Por otra parte, se propugna la elaboración de Planes Estratégicos y nuevos planes de desarrollo a largo plazo en las ciudades, en un contexto de competitividad global (real o ficticio), buscando especialmente el partenariado público-privado (implicar a los grupos privados en grandes proyectos inversores) y utilizando siempre la nueva palabra fetiche: desarrollo sostenible.

2. Desde las empresas. Era necesario desarrollar una nueva filosofía empresarial, una nueva ética dentro del libre mercado ante su desprestigio creciente, que mostrara una cara más amable que la que tenía el capitalismo financiero, desprestigiado por sus tendencias ultracompetitivas, especulativas y de la ingeniería contable: se crea la Responsabilidad Social Empresarial y la Corporativa (RSE, RSC).

3. Del tercer sector. Y en tercer lugar, por el lado de los de abajo, las asociaciones ciudadanas no lucrativas ¿qué hacer ante estas situaciones? La respuesta vino con la creación de nuevas ONG, nuevos movimientos de solidaridad que recorren imparables el mundo occidental desde los años 90: el movimiento del 0,7\%, 
las organizaciones no gubernamentales de cooperación y ayuda al desarrollo y las nuevas asociaciones "de voluntariado", como nueva base político-social que es o quiere ser a la vez alternativa y complemento asumible al propio sistema. Desde los ámbitos del poder se da un nuevo protagonismo a las asociaciones no lucrativas, especialmente a las que se definan como "apolíticas".

Fueron tres respuestas diferentes y complementarias desde cada sector-ámbito de la sociedad. Pero no desde todos los estados y gobiernos se apostó por estos modelos de cambio.

\section{¿Capitalismo único?}

¿Cuáles son las posiciones predominantes en el sistema actual? El capitalismo internacional está principalmente significado por la especulación financiera, pero los otros modelos coexisten en él. El capitalismo de consumo ha coexistido con el productivo desde su misma creación (impulso al consumo desde los años 30 y especialmente desde los 50 paralelo al desarrollo del Estado de Bienestar). Desde los años noventa el crecimiento del que podemos denominar "capitalismo especulativo" es el que lo convierte en predominante, sin por ello dejar de coexistir con el productivo y el de consumo. Por ejemplo en la pasada década ya se calculaba que más del $40 \%$ de las transacciones económicas en la Bolsa de Estados Unidos son simplemente especulativas. A nivel mundial son billones de dólares diarios que se mueven con el único objetivo de comprar para vender a las pocas horas 0 a los pocos minutos y haber obtenido una sustancial ganancia. "Como han demostrado Gary Gorton y Andrew Metrick, de la Universidad de Yale, en 2007 el sistema bancario estadounidense dependía esencialmente de las transacciones 'repo', en las que las instituciones financieras venden activos a los inversores prometiéndoles recomprarlos al cabo de poco tiempo (a menudo, un solo día)" (P. Krugman 2009)`. ¿Dónde está la inversión para la mejora productiva, el libre mercado basado en la oferta y demanda de los mejores productos en estas transacciones? Como concluye Krugman citando a Turner en el mismo artículo "buena parte de lo que hacen Wall Street y la City es 'socialmente inútil'."'

Estas tendencias especulativas globales no son incompatibles con la convivencia de diferentes formas políticas de capitalismo y de relativo libre mercado. El incremento de las desigualdades en el capitalismo especulativo globalizado es evidente a nivel mundial pero adopta formas muy diferentes según países y regiones. Los puntos de partida son bien distintos y las formas de adaptación y salida de la crisis actual también. Desde países con más Estado de Bienestar y más igualitarios, como los nórdicos europeos

\footnotetext{
${ }^{1}$ Paul Krugman, premio Nobel de Economía, apoya en este artículo la creación de una tasa contra la especulación, a partir de la conocida como "Tasa Tobin" por ser ya propuesta en 1972 por el también Premio Nobel James Tobin.
} 
y Japón (con poca desigualdad de renta), hasta los más desigualitarios, como Estados Unidos, Reino Unido, Portugal, México o Brasil,... pasando por los que están en posiciones intermedias, como España y buena parte de los europeos. En este sentido es interesante la publicación de estudios sobre la relación directamente proporcional entre felicidad —calidad de vida y la equidad interna por países, como el realizado por R. Wilkinson y Kate Pickett (2009) donde se demuestra esta correlación (después de haber estudiado y comparado más de 150 investigaciones independientes): los países con mayores desigualdades internas son los que tienen más malestar ciudadano y más enfermedades personales y sociales, medido con diferentes variables: salud física y mental, obesidad, esperanza de vida, criminalidad,... Estos parámetros no dependen tanto de que un país sea rico o pobre sino de las diferencias socioeconómicas internas. Diferencias que son muy diferentes entre unos países y otros.

Las distancias en los ingresos salariales entre los que más ganan y los que menos también han ido creciendo ininterrumpidamente en las últimas décadas, paralelamente a los procesos de globalización. Según Zigmunt Bauman: "La brecha entre los ricos y los pobres, y entre los más ricos y los más pobres se amplía literalmente de año en año, tanto dentro de las sociedades como entre ellas, en una escala global y dentro de cada unidad estatal. En Estados Unidos, el país más rico del mundo, y al mismo tiempo la capital mundial de los conflictos de intereses y las batallas reivindicativas, la renta de los jefes de las grandes empresas en 1999 era cuatrocientos diecinueve veces superior a la de los trabajadores manuales (sólo hace diez años era únicamente cuarenta y dos veces superior)" (Bauman 2006:82) [los datos citados proceden de Loic Wacquant, Las cárceles de la miseria]". O, consultando otra fuente, Robert Reich en Wall Street Journal (citado por Vidal-Beneyto, 2009): "Un director ejecutivo medio gana hoy 364 veces más que un empleado medio, cuando hace 40 años apenas llegaba a 20 veces más".

El aumento de las diferencias socioeconómicas es constantemente corroborado por numerosos estudios y publicaciones, pero la comparación entre países y sus consecuencias es menos publicitada. Sobre la comparación de las diferencias salariales entre los que más y menos ganan en el interior de cada país podemos señalar el estudio de Ronald Buchanan (2004), "The salary report", donde realiza un análisis sobre los ingresos brutos de los ejecutivos, cuadros medios y trabajadores en diferentes países. A partir de sus datos salariales sobre los ingresos absolutos en cada país hemos realizado un cálculo de cuatro naciones significativas, llegando a las siguientes cifras relativas: los ejecutivos (Chief Executive Officers) de México ingresan de media 63 veces el salario medio de los trabajadores (Workers). En Estados Unidos los ejecutivos ingresan 44 veces más, en España 22 veces y en Japón 9,5 (elaboración propia a partir de los datos de R. Buchanan 2004). Estos datos, igual que los estudios incluidos en el citado de Wilkinson y Pickett, nos dan una idea de las enormes diferencias salariales y de equidad también entre países que se incluyen habitualmente en el mismo modelo económico (capitalismo liberal-libre mercado). Cuando hablamos de países desarrollados occidentales estamos metiendo 
en el mismo saco modelos económicos y sistemas sociales bastante diferentes. Parece que el pensamiento único no se corresponde con la realidad y sí, más bien, con la que algunos quieren que exista.

\section{Posiciones hegemónicAs Y TEtRALEMA de tendencias}

Desde un punto de vista más político y no sólo sobre la equidad interna, podemos observar las diferentes tendencias en las posiciones de los sistemas socioeconómicos dentro del capitalismo actual. Bajo el vector especulativo predominante a nivel internacional, podemos diferenciar al menos cuatro posiciones o tendencias dominantes, desde las más "socializantes" hasta las más neoliberales. No podemos quedarnos en sólo dos tendencias, una más de izquierdas, socialdemócrata, y otra más de derechas, neoliberal. Con ser cierta para muchos análisis es claramente insuficiente, si queremos tener una visión sobre las posiciones del conjunto de países. Por lo que utilizaremos la realización de un tetralema, donde podremos colocar al menos cuatro posiciones o tendencias diferentes que se corresponden a diferentes lógicas y no solo a la tradicional de izquierda y derecha. Tomando como referencia metodológica a Tomás R. Villasante, podemos indicar que la complejidad de la realidad no se puede reducir a binomios contrapuestos, "no estamos hablando de una dialéctica simple, de corte hegeliano, donde tesis y antítesis nos llevan a una síntesis, muy determinada. Estamos ante dialécticas orientales más paradójicas, donde los contrarios se abren a varias soluciones posibles. En Ibáñez los dilemas se convierten en tetralemas." (Villasante, 2002b:90). Cuatro líneas estratégicas diferentes marcan los sistemas capitalistas actuales, pero todas están interconectadas y con crecientes intercambios, no solo comerciales (por ejemplo todos sus representantes se reúnen para debatir conjuntamente en el foro anual de Davos y en otras conferencias internacionales).

Tenemos por un lado, en el eje horizontal del tetralema (figura 1), las posiciones más nacionalistas: a la izquierda las que defienden un capitalismo de Estado, socializante 0 de izquierdas, con diversas posiciones: autoritarias históricamente consolidadas (China) 0 tendenciales (Venezuela,...), donde existe libre mercado pero bajo control estatal y convive con un relativo Estado de Bienestar o proteccionista, con rasgos propios y diversos. A la derecha tenemos a los neocons, a los conservadores nacionalistas y ultranacionalistas, partidos y/o gobiernos en diversos países (desde el Tea Party a los regímenes de algunos países árabes, teocracias,...).

En el otro eje, vertical, tendríamos la contraposición de dos posiciones: en la superior la de los partidarios de la desregulación total, del neoliberalismo puro y duro (globalización sin fronteras, encabezada por las transnacionales) y en la inferior las de los partidarios de un capitalismo regulado o, mejor, auto-regulado según sus intereses, manteniendo un mínimo Estado de Bienestar. 
Figura 1.

Posiciones y tendencias en el sistema capitalista mundial

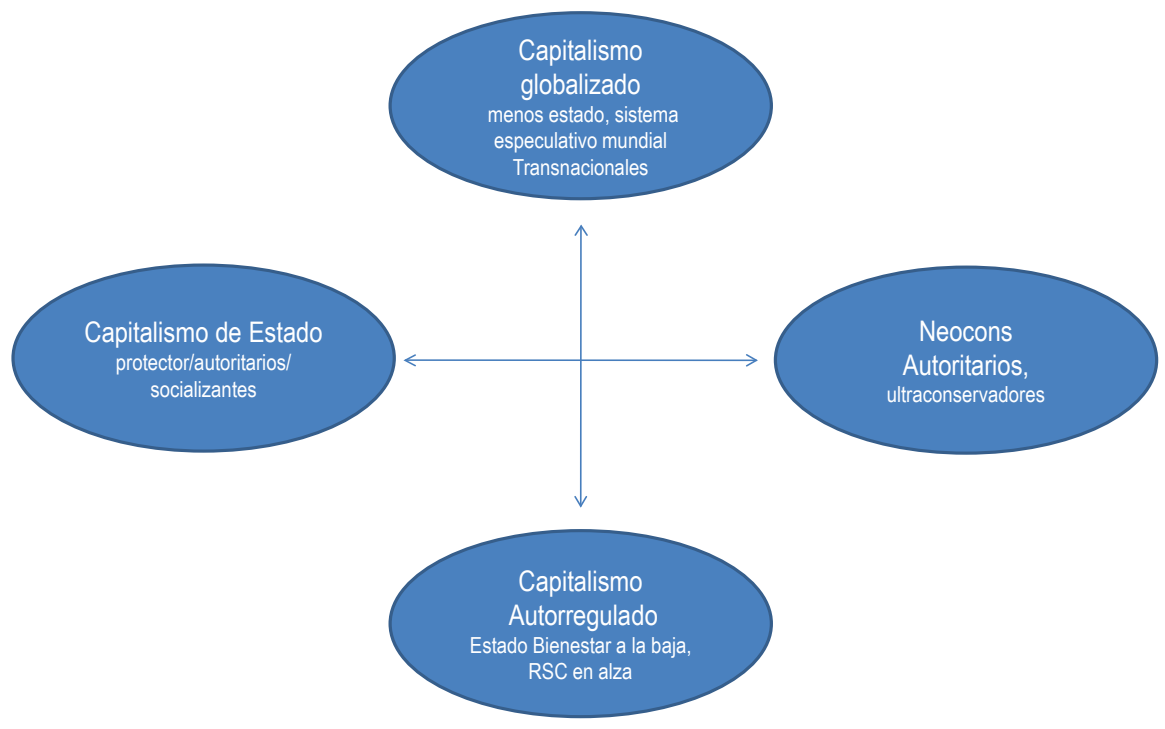

Fuente: reelaboración propia a partir de Villasante, Alberich y Espadas (2010)

El enfrentamiento entre estas dos últimas posiciones es un tanto superficial ya que las dos conviven en numerosos países y, aunque se corresponden con las tradicionales de partidos conservadores-liberales y socialdemócratas-laboristas, en la mayoría de los territorios la aproximación entre ambos (conquista del centro) es notable pero siempre hacia arriba: las terceras vías asumen las desregulaciones, las reformas estructurales, flexibilidad... como propias, de tal forma que desde los años 80 el Estado de Bienestar se ha ido reduciendo constantemente: cuando gobiernan las derechas porque va en su ideario, cuando les toca a las izquierdas porque no se atreven a reformar lo hecho por los anteriores gobiernos o incluso lo hacen ellos porque se ven obligados por los "mercados", por las crisis o por los inversores internacionales (especuladores). Así la Responsabilidad Social Corporativa y la Empresarial aparecen como objeto de adulación y salvación: ya que "no podemos" aumentar o recuperar el papel del Estado (redistribución, justicia social,...) que sean las empresas las que al menos dediquen algo a ello y desde las Administraciones públicas colaboraremos. El Estado cada vez tendrá menos poder (coincidencia de posiciones) pero las empresas paliarán las situaciones más lace- 
rantes, bien directamente o a través de asociaciones, ONG y voluntariado. Además la RSC nos servirá, como comentamos, para cambiar la imagen social empresarial, tanto la pública como la interna, pactar con los sindicatos y trabajadores más activos temas laborales y sociales, y con estos y otros agentes sociales realizar acciones de desarrollo social y sostenible.

\section{Capitalismo europeo y Capitalismo moderno. Sin RSC no hay Salvación POSIBLE}

El capitalismo más innovador ha encontrado en la RSC su tabla de salvación pública. Los grandes filántropos y sponsors tienen una imagen pública de prestigio que contrasta con la del empresariado tradicional o la de las empresas y bancos en un mundo hípercompetitivo y especulativo. A través de un discurso implícito que nos dice: queremos menos impuestos, menos costes fiscales para las empresas y más facilidades para ganar más y más dinero... y no os preocupéis por la reducción del Estado de Bienestar que una parte de ese dinero, libremente, lo dedicaremos a obras sociales, a las que decidamos apoyar o creemos nosotros directamente (fundaciones de las propias empresas), que correspondan con nuestros objetivos y métodos y con las personas que nosotros decidamos poner ahí. Así paliaremos lo que el Estado no hace.

Recuerda a lo que tradicionalmente hacían las esposas de los jefes de Estado, de la aristocracia y de los hombres de negocio, dedicándose a las obras de caridad, a "ayudar a los pobres" y a las obras sociales. Ahora también, pero ya sin diferencias de género y bajo el paraguas más moderno de la RSC.

Estos aspectos sobre el origen y razón de ser de la RSC no son óbice para que analicemos lo que hay dentro de esta ética y "filosofía empresarial" y veamos qué es lo que hay en ella, en sus diferentes posturas -nuevas o tradicionales-, en sus prácticas y en sus relaciones con el Tercer Sector. La RSC está aquí, ahora a nivel global, y ha llegado para quedarse.

Las causas últimas individuales de por qué un empresario o un banquero impulsa la RSC son importantes pero no tanto: lo que más nos interesa es saber cómo lo hace, con quién y para qué; no si se lo cree personalmente más o menos. Así podremos analizar qué tipo de proyectos, dónde, con qué objetivos (ayudas sociales, paliar situación de pobreza, protección de la naturaleza o proyectos de ecodesarrollo,...) y con quién los hace 0 está dispuesto a realizarlos: si con asociaciones, movimientos sociales y sindicatos o, por ejemplo, sólo con grupos de voluntariado creados ad hoc, o con todos, con los difusos grupos de interés -los denominados stakeholders. Para las asociaciones y movimientos sociales la RSC se ha convertido en un nuevo campo que ha ampliado el que ya existía, de tradición, en la colaboración con empresas y sociedades de lucro. La RSC ha ampliado las posibilidades de financiación de las asociaciones, de todo tipo (el denominado Tercer Sector) y no sólo eso: les ha abierto o posibilitado nuevas vías de acción y penetración social, facilitando la consecución de sus objetivos. 
Dentro de la RSC podemos distinguir al menos cuatro tendencias. Siguiendo a Villasante, Alberich y Espadas (2010:178-182), estas cuatro posiciones las podemos resumir asi:

1. Capitalismo de ficción. RSC como puro marketing. Por ejemplo, los telemaratones solidarios televisivos o el hazte donante de... para acciones de solidaridad de cualquier empresa. También casos como el de la marca tabacalera Fortuna que hace ya bastantes años anunció el $0,7 \%$ de su facturación para ayuda al desarrollo. Solo alguna ONG picó el anzuelo. El Código de Conducta de la Coordinadora de ONGD puso coto a estas prácticas. Los ejemplos de las contradicciones en estas campañas de puro marketing serían numerosos.

2. Filantropía que desgrava. Desgravar impuestos: RSC y las acciones de caridad. Hay prestigiosas empresas españolas y europeas que han querido dar un paso más. Que no sea sólo marketing sin escrúpulos. Han creado Fundaciones para actuaciones internas y algunas externas. En ellas ha tenido importancia la base ideológica de muchos de sus dueños o directivos (solidaridad cristiana, socialdemócrata,...) que han querido imbuir a sus corporaciones de una línea de desarrollo de su filosofía empresarial, encontrando una comunión entre sus ideas, los proyectos de caridad o asistenciales y la desgravación de impuestos para empresas, mediante el patrocinio.

3. Economía local y Administración endógena. Pymes y RSC como parte del desarrollo local. Las pequeñas empresas y de comerciantes, empresas de servicios de proximidad, con arraigo local han practicado desde siempre la RSC en algunos de sus postulados, antes de que se inventara y se le diera ese nombre. La colaboración en iniciativas sociales, culturales, deportivas... por parte de comerciantes y del empresariado local es una tradición en nuestro país. Evidentemente esto ha ido parejo a la búsqueda de un prestigio en el entorno cercano, entre la clientela real y potencial. No existe en nuestro país un municipio o barriada en que no haya empresarios locales que colaboren con las fiestas, los clubes deportivos, actividades culturales o campañas de solidaridad... Su relación con el tejido social es determinante.

4. Planes comunitarios, asociaciones y plataformas de movimientos sociales. Hay ejemplos en que iniciativas locales se plantean ir más allá de una aportación como marketing, desgravación o como una solidaridad local con alguna causa social. Es el caso de artistas y empresarios filántropos que dedican parte de sus trabajos y beneficios a entidades sociales y de desarrollo, que son los que deciden el sentido de las inversiones y de los nuevos proyectos. En España hay casos conocidos. En la película el Milagro de Candeal se ilustra la posición de Carlihnos Brown que, como la de otros grupos musicales de Salvador de Bahía, invierten una parte de sus beneficios en la mejora de su barrio de origen, dentro de una concepción recuperadora de las tradiciones e identidades locales. La clave está en saber quién decide sobre las inversiones, y cómo se hace el procedimiento (¿democrático, participativo?) para que no se reproduzcan clientelis- 
mos, nepotismos, etc. Del quién y el cómo dependerá que se produzcan (o no) procesos reales de empoderamiento ciudadano.

Por supuesto también hay casos en que las cuatro alternativas de RSC están interrelacionadas o son complementarias unas de otras. Las fundaciones de la multinacional Telefónica y Movistar se encontrarían principalmente en la opción de puro marketing. Sin embargo contrataron a Carlihnos Brown para el lanzamiento mundial (en 2005/6) del nuevo logotipo Movistar, constituyendo una de las campañas de marketing más costosas de la historia. Y Carlihnos intervino obteniendo fondos para su plataforma de desarrollo de Candeal, que sería un ejemplo de la cuarta posición de RSC.

\section{ASOCIACIONISMO Y RSC}

Para muchas asociaciones y movimientos sociales, puesto que existe la RSC, lo que hacen es utilizarla. No es solo una oportunidad, es casi una obligación; especialmente para las de acción social y para las que trabajan con personas desfavorecidas o en exclusión social. Desaprovecharla sería no solo miope sino injusto. Esto no es una crítica a algunas asociaciones que rechazan los patrocinios o las colaboraciones económicas de empresas y gobiernos para mantener su total independencia de una forma más pura, como hacen Amnistía Internacional, Green Peace u otros movimientos sociales. Depende de cada ámbito y de los objetivos de cada entidad. Lo que se quiere decir es que recibir dinero o aportaciones, privadas o públicas, no tiene por qué significar perder la independencia o menoscabar los valores fundacionales de la entidad.

¿Cuáles son los límites? Básicamente de dos tipos: no olvidar las responsabilidades éticas y las reivindicaciones/objetivos sociales que estén en la misión y la visión de la entidad. No apoyar ni participar en cualquier proyecto de RSC. Es necesario analizar y discriminar.

La transparencia en la gestión y la elaboración y cumplimiento de Códigos de Conducta es esencial en el Tercer Sector y en ellos se deben de determinar los límites en la colaboración con empresas privadas y administraciones públicas. Si esto es cierto para cualquier tipo de entidad del Tercer Sector lo es mucho más cuando hablamos de las organizaciones de "acción social", las que se dedican específicamente a cambiar las condiciones de vida y a paliar las situaciones de personas excluidas o discriminadas, ya sea por su situación económica, o por origen, edad, discapacidad, orientación sexual, etc. Por poner un ejemplo: el que cualquier empresa subvencione o patrocine eventos deportivos o de ocio en el ámbito local o regional (en colaboración con clubs, agrupaciones deportivas, asociaciones de festejos,...) se mueve en un espectro muy amplio. Pero las organizaciones y proyectos de acción social deberían de rechazar la colaboración o el patrocinio de determinadas empresas, bancos o administraciones 
denunciados por sus malas prácticas (especulación, corrupción, incumplimiento de la legislación laboral, social...), si no quieren ser utilizados, como poco, para "lavar" la imagen de esos especuladores o presuntos corruptos. Lo mismo que una asociación ecologista o de defensa de la naturaleza no puede tener patrocinios de empresas que se dedican a la deforestación o a la explotación irracional de bosques y zonas naturales.

\section{LAS MÚLTIPLES RESPUESTAS DESDE LOS MOVIMIENTOS SOCIALES}

Hay que tener en cuenta que, como hemos visto, hay diferentes tipos de RSC, pero también son múltiples las posiciones y respuestas desde los movimientos sociales. Sería miope quedarse en un simple debate de sí o no a la colaboración con empresas o instituciones. Ante este dilema, como ante otros, los movimientos sociales han sabido ver que hay más posturas que el sí o el no. Una de las capacidades de los nuevos movimientos ha sido el que, frente al poder o respecto de actuaciones concretas, no sólo se puede decir sí o no. Los posibles tipos de respuestas dadas son al menos cinco:

- Sí. Respuesta de los afines.

- No. Opuestos. Ambas (si/no) están en la lógica del "nosotros" o "ellos".

- El "sí pero no"; el sí, pero no así; acepto las reglas pero no lo que se propone, puedo utilizarlas para denunciar que el poder no las cumple. Por ejemplo cumplir escrupulosamente las reglas de seguridad paraliza el sistema, huelgas a la japonesa...

- El "no pero sí", no a las reglas, leyes,... cumplo lo planteado pero denunciando las reglas del juego, las contradicciones del sistema.

- El "ni sí ni no", no acepto las reglas del juego, no acepto su lógica. Es más: la denuncio por artificial; es un juego que quiere hacer creer a la ciudadanía que solo ustedes y sus preguntas existen, que solo hay el sí y el no. Hay otras alternativas. $Y$ "el no acepto la pregunta" porque mis preguntas y mis respuestas son otras. Puede dar lugar a posiciones de pasotismo (paso del sistema actual) o por contra, de construcción de otras alternativas diferentes, nuevas.

Estos tipos de respuesta y de posiciones sociales han sido desarrollados por T. Villasante a partir de Jesús Ibañez (Villasante, 2002:34-36). Así, frente al poder, tenemos las conductas conversas (refuerzan el poder), el sí y el más que sí; perversas (invertido, respuestas violentas, en la práctica suelen reforzar el poder) —el no radical, el no por el no, ambas se fijan más en el quién hace la propuesta que en sus contenidos; subversivas (ironizando) y reversivas (humorístico), darle la vuelta a los argumentos, estas dos últimas estarían en el no pero sí y el sí pero no. Todas han estado en algún momento presentes en los movimientos sociales desde los años setenta. 
Los tetralemas citados anteriormente serían una aplicación concreta a partir de argumentos y posiciones contrapuestos que tratan de superar el simplismo del sí o el no. J. Galtung propuso desde los años ochenta un análisis más complejo y sistémico de la realidad que las simples disyuntivas positivo-negativo, izquierda-derecha, Estado-Mercado. Para superar conflictos sociales concretos y el análisis de contradicciones simples se plantean los tetralemas, se busca nuevas alternativas y posiciones que superen las actuales de partida (sí o no a algo). En su posición más elaborada Galtung (2008) plantea el Método Transcend buscando nuevas alternativas diferentes que traten de integrar y superar las posiciones contrapuestas de partida, transcendiéndolas. Por ejemplo ante el debate en una asociación sobre si colaborar o no con empresas (el sí o el no a la RSC) cabría plantear: dejemos de lado el sí y el no y analicemos en qué condiciones, con qué empresas, para qué fines, con qué obligaciones.

\section{TIPOLOGÍA ASOCIATIVA}

Hay muchos tipos de clasificación de las asociaciones: por sus objetivos, por el tipo de actividades (sectoriales, temáticas), por sus destinatarios (grupos de población, género,...), según sus reivindicaciones y formas de actuar, movilizarse, etc. Mirando el cómo funcionan, qué tipo de relaciones tienen en su interior (entre junta directiva, socios, voluntariado...) y cómo se relacionan con el exterior (con otras entidades, con las instituciones y con la población), Tomás Villasante planteó considerar cuatro tipos de entidades: autoaislados, populistas, gestionistas y ciudadanistas (Villasante et al, 1989). De los análisis realizados en los años 80 y 90 podemos resumir estos cuatro modelos de conjuntos de acción más típicos de las asociaciones:

- $\quad$ Autoaislados. Cuando una asociación se relaciona poco con otras y tiene poca relación con la base potencial y con otros grupos. Su relación con las instituciones es escasa y conflictiva.

- Populistas. El Grupo Formal dirigente es pequeño y se relaciona muy bien con la base. Casi no existen sectores activos. Se mantienen relaciones intensas con las instituciones consiguiendo reivindicaciones (subvenciones, inversiones...) y se alternan buenas relaciones con conflictos.

- Gestionistas. El grupo dirigente es un sector activo que gestiona muy bien pero ha perdido, o disminuido, su horizonte reivindicativo e ideológico (modelo predominante).

- Intentos Ciudadanos. Las propuestas ciudadanistas irían en el sentido de crear movimiento ciudadano, siendo conscientes de ello. Cuando un Grupo Formal (dirigentes) se preocupa por ampliar tanto su sector activo como su base, aplicando técnicas participativas, de formación, etc., buscando también una buena relación con otras asociaciones y grupos formales e informales. Su relación con las instituciones es de colaboración pero sin perder el sentido crítico y la independencia.

En la realidad social estos cuatro modelos no se dan puros: se entremezclan y cada asociación puede tener notas o características de cada uno de ellos (Alberich, 
2007:195,196) o evolucionar entre unos modelos y otros. Si miramos al conjunto del mundo asociativo y del Tercer Sector, el gestionista es claramente el predominante desde los años noventa, incluso en algunos casos en su formulación de asociación-empresa, como entidad que se registra legalmente como asociación sin ánimo de lucro pero es a casi todos los efectos una empresa. En el sentido opuesto tendríamos la aparición de nuevos movimientos ciudadanos de protesta, desde los movimientos altermundistas y los foros sociales a los recientes del 15M, plataformas antidesahucios.

\section{DISCAPACIDAD Y ASOCIACIONISMO}

La actuación inteligente de movimientos doblemente reivindicativos/de denuncia —ciudadanistas- a la vez que gestionistas, la podemos identificar con numerosas asociaciones relacionadas con la discapacidad. Adoptando posturas que están presentes en los enfoques concretos y que podríamos denominar, también doblemente, como subversivas y reversivas, según las definiciones positivas de estos conceptos antes citadas (subvertir el orden establecido - injusto-, desde dentro y/o darle la vuelta). Son diferentes posiciones frente al poder y un sistema que de partida es injusto y discriminatorio.

Los cuatro diferentes tipos de RSC que hemos visto son utilizados por el asociacionismo de acción social y nos vamos a fijar específicamente en el relacionado con la discapacidad. Como hemos visto, la RSC forma parte de las estrategias del poder, que trata de utilizar el asociacionismo para su lavado de imagen. Por su parte las asociaciones tratan de utilizar la RSC en su propio beneficio y sin perder sus valores éticos (aspecto que no siempre consiguen).

El asociacionismo de la discapacidad ha tenido internacionalmente y desde hace bastantes años una buena imagen que ha sabido aprovechar para sus fines. En el caso español se cuenta además con una larga tradición tanto de entidades gestionistas como de reivindicativas, y de ambas. Empezando por la ONCE, cuya acción para-estatal la convirtió en una institución semipública a la vez que un modelo envidiado por otras organizaciones y países. Promovió la creación de una corporación empresarial que funcionó como lobby 0 grupo de presión, con sus luces y sombras, durante bastante tiempo (especialmente en los años 80-90). La creación, desde los años setenta, de otras federaciones sectoriales provinciales y autonómicas de asociaciones de personas con discapacidad según sus diferentes tipos (física, intelectual, sensorial) cambió la estructura de estos movimientos asociativos de personas afectadas y sus familias, consolidando una estructura doble, sectorial (temática) y territorial, extendida por todo el Estado. Posteriormente se creó una plataforma de encuentro unitaria, estable y reconocida institucionalmente, el CERMI, Comité Español de Representantes de Personas con Discapacidad, en el que están representadas unas 5.000 asociaciones y entidades sociales del mundo de la discapacidad, a través de federaciones y plataformas unitarias que representan a unos tres millones y medio de personas (www.cermi.es).

El triunfo en muchos aspectos de estos movimientos ha sido evidente, pero a partir del trabajo constante desarrollado a lo largo de varias décadas. Son indiscutibles los 
cambios sociales en la percepción sobre la discapacidad, la imagen de la persona discapacitada, el cambio en el lenguaje, en la formas de denominación, y los cambios en el reconocimiento de sus derechos económicos y sociales: pensiones, eliminación de barreras arquitectónicas, de barreras en la contratación laboral, de desarrollo de programas específicos de discriminación positiva, los cambios incluidos en la LAPAD (Ley 39/2006 de Promoción de la Autonomía Personal y Atención a las Personas en Situación de Dependencia). En definitiva, mayoritariamente se ha comprendido que estos cambios no sólo eran necesarios, de justicia para con un grupo de población específico numeroso (9\%), sino que además estos cambios nos beneficiaban al conjunto de la población.

El éxito del modelo desarrollado por asociaciones de personas con discapacidad ${ }^{2}$ podemos decir que es cuádruple:

1. Por un lado han conseguido llegar a tener una gran estructura organizativa, a todos los niveles (territorial y sectorial), con múltiples funciones y servicios para las personas afectadas por alguna discapacidad y para sus familiares, y con estructura nacional e internacional.

2. Estos servicios no son sólo para prestar ayudas también lo son, y esto es más sobresaliente, para poner en práctica la integración directa mediante la creación de centros y empresas donde trabajan personas con discapacidad; empresas de inserción, centros especiales de empleo, enclaves laborales... en todos los sectores -aunque en el sector servicios sería predominante (hostelería, distribución, logística, etc.-, donde entran en el juego de mercado en competencia con otras empresas. Aunque tengan alguna subvención pública, la viabilidad de estos proyectos empresariales ha dependido de su gestión eficaz y eficiente. Han creado espacios alternativos de autogestión de nuevas organizaciones, a la vez que una estructura productiva gestionista. Otro ejemplo sería la de su presencia en los medios de comunicación, con programas y espacios propios, como programas de radio — de gran calidad — realizados por personas con DI/EM que cumplen una función terapéutica, además de publicitar sus propuestas, actividades y reivindicaciones. Realización de actividades dramáticas y de expresión corporal, desde grupos de teatro y danza propios, y en todas las expresiones artísticas ${ }^{3}$.

\footnotetext{
${ }^{2}$ Tal vez deberíamos de hablar en plural, de "modelos" porque no podemos decir que exista un solo modelo predominante, pero sí podemos describir algunas características comunes en buena parte de las entidades conocidas. Por ejemplo en el caso de la provincia de Jaén tenemos asociaciones y federaciones, como Apromsi y FEJIDIF, que serían ejemplos de buenas prácticas de los modelos asociativos que se citan.

${ }^{3}$ Desde hace bastantes años existen múltiples experiencias, como programas de radio, ejemplo "La Vitrina" en Radio Villalba (107.4 FM Madrid). Algunos de estos programas radiofónicos han recibido diversos premios por su calidad. Por otra parte hay ya numerosos ejemplos de "Festival de Teatro Especial" como el organizado por la Fundación ANADE en la Sierra madrileña, la Muestra de Teatro Especial en Madrid, el Festival Paladio Arte de Segovia, etc.
} 
3. Simultáneamente han conseguido mantenerse en un cierto nivel de movimiento social: reivindicativo, de denuncia, protesta y propuesta. Desde los trabajos de investigación y denuncia más concretos, como publicitar los edificios públicos donde aún existen barreras arquitectónicas, donde no se cumple la legislación, acciones directas como el poner una pegatina señalizando los coches mal aparcados que impiden el paso (el sí pero no, reversivo), hasta influir/participar en la redacción de nuevas normativas y legislaciones, como en la citada Ley 39/2006 LAPAD — sobre autonomía y dependencia, aunque su influencia no sea suficiente o la que ellos deseaban (el no pero sí, aun no estando de acuerdo en la redacción final de la Ley la utilizo lo más posible y denuncio sus contradicciones).

4. Y en cuarto lugar, también han conseguido la integración de personas con discapacidad en otras asociaciones, movimientos y organizaciones, que se vea como algo normalizado la integración social. Por ejemplo que haya personas con discapacidad en las juntas directivas de las asociaciones locales ciudadanas o el que una persona con discapacidad no sólo física sino intelectual participe como ponente en unas Jornadas de debate, de cualquier tipo, está empezando a pasar de ser algo extraño o marginal a convertirse en lo habitual. El que una persona en silla de ruedas esté como uno más en las reuniones en las plazas del movimiento de los indignados del 15M o que en las asambleas se utilice el lenguaje de signos.

El que las asociaciones gestionen los servicios necesarios para personas con discapacidad, de forma mejor y más económica que las Administraciones Públicas, no quita la responsabilidad del Estado. La responsabilidad pública es clara y es quien tiene que poner las reglas y los controles. Pero las asociaciones no se han abstenido de participar, asumiendo un papel protagonista y de cogestión en los servicios, a pesar de los peligros que conlleva. No se han querido quedar en actitudes ni de autoaislamiento ni populistas. También han sabido transcender las cuatro posiciones típicas de RSC, superándolas en algunos aspectos criticables y haciéndolas suyas con un desarrollo que les es propio.

En conclusión, las asociaciones de acción social y específicamente las de personas con discapacidad han conseguido tener un asociacionismo propio bien organizado y representativo, con legislación social específicamente dirigida y adaptada; a la vez que han penetrado claramente en el conjunto de la organización social y, como parte de esta, en sus estructuras económicas, empresariales, asociativas e institucionales.

\section{REFERENCIAS BibLIOGRÁFICAS}

Alberich, T. 2007. "Contradicciones y evolución de movimientos sociales en España". Documentación Social 145. Madrid: Cáritas Española Ed.

Bauman, Z. 2005. Vidas desperdiciadas. La modernidad y sus parias. Barcelona: Paidós Estado y Sociedad.

Bauman, Z. 2006. Comunidad. En busca de seguridad en un mundo hostil. Madrid: Siglo XXI. 
Buchanan, R. 2004. "The salary report" Business Mexico. Allbusiness. Consulta de marzo 2011 http:// www.allbusiness.com/human-resources/compensation-salary/207587-1.html.

Castells, M. 2010. Comunicación y Poder. Madrid, Alianza Editorial.

De la Corte Ibáñez, L. y A. Giménez-Salinas. 2010. Crimen.org. Barcelona: Ariel.

Galtung, J. 2008. 50 años, 25 paisajes intelectuales explorados. Puebla, México: Transcend University Press (www.transcend.org).

García-Rosales, C. y M. Penella. 2011. Palabras para indignados. Madrid: Mandala Ediciones.

Garzón, B. 2005. Un mundo sin miedo. Barcelona: Plaza \& Janes.

Forgione, F. 2010. Mafia Export: Cómo la 'Ndrangheta, la Cosa Nostra y la Camorra han colonizado el mundo. Barcelona: Anagrama.

Navarro, V. 2006. El subdesarrollo social de España. Causas y consecuencias. Barcelona: Ed. Anagrama.

Navarro, V. y M. Tur. 2011. “¿Por qué tanta desigualdad en España?”. Le Monde Diplomatique en Español Junio.

Krugman, P. 2009. “Cobrar impuestos a los especuladores”. Madrid, El País Negocios (pag. 21) 6 de diciembre.

Sassen, S. 2007. Una sociología de la globalización. Madrid: Katz editores.

Taibo, C. 2002. Cien preguntas sobre el nuevo desorden. Madrid: Punto de Lectura.

Vidal-Beneyto, J. 2009. "La abominación que no cesa”. El País, 12.09 .09 (pag. 27).

Vidal-Beneyto, J. 2010. La corrupción de la democracia. Madrid: Libros de la Catarata.

Villasante, T. R. 2002. Metodologías y Presupuestos Participativos. Construyendo Ciudadanía/3. España, IEPALA Editorial y CIMAS.

Villasante, T. R. 2002b. Sujetos en movimiento. Construyendo Ciudadanía/4. Montevideo: Edit. NordanComunidad.

Villasante, T. R., T. Alberich y Á. Espadas. 2010. "Responsabilidad Social Corporativa, Sostenibilidad y Alternativas Locales de Desarrollo" Pp. 178-182 Responsabilidad Social, una reflexión global sobre la RSE. Madrid: Pearson Educación.

Villasante, T. R., J. Camacho, E. Trabada, F. Díaz y J.C. Sanroman. 1989. Revista Salida de Facmun. Madrid: Facmun.

Wilkinson, R. y K. Pickett. 2009. Desigualdad. Un análisis de la (in)felicidad colectiva. España: Turner Noema.

Tomás Alberich es Doctor en Sociología por la Universidad Complutense de Madrid (UCM, 1994). Magister en "Investigación, Gestión y Desarrollo Local", título propio de la UCM (1998). Profesor en la Universidad de Jaén desde 2003, Área de Trabajo Social y Servicios Sociales. Líneas de investigación: Participación Ciudadana, Movimientos Sociales y Tercer Sector; Metodologías Participativas de Investigación y del Trabajo Social.

RECIBIDO: 04/03/2013

ACEPTADO: 20/03/2014 